\title{
NEW RESULTS FROM THE NOAA CREST LIDAR NETWORK (CLN) OBSERVATIONS IN THE US EASTCOAST
}

\author{
*Fred Moshary ${ }^{a}$, Zaw Han ${ }^{a}$, Yonghua Wu ${ }^{a}$, Barry Gross ${ }^{a}$ \\ ${ }^{a}$ Optical Remote Sensing Lab., City College of New York, NY, 10031, USA *moshary@ccny.cuny.edu \\ Daniel Wesloh $^{\text {b }}$, Raymond M. Hoff ${ }^{\text {b }}$, Ruben Delgado ${ }^{b}$ \\ ${ }^{b}$ Physics Department and Joint Center for Earth Systems Technology, \\ University of Maryland, Baltimore County, MD USA 21250 \\ Jia Su$^{\mathrm{c}}$, Liqiao Lei ${ }^{\mathrm{c}}$, Robert B. Lee III' ${ }^{\mathrm{c}}$, M. Pat McCormick ${ }^{\mathrm{c}}$ \\ ${ }^{c}$ Department of Atmospheric and Planetary Sciences, Hampton University, Hampton, VA, 23668 USA \\ Jesus Diaz ${ }^{d}$, Carlos Cruz ${ }^{d}$, Hamed Parsiani ${ }^{d}$ \\ ${ }^{d}$ Department of Electrical and Computer Engineer, University of Puerto Rico, Mayagüez (UPRM) \\ Campus, PO Box 9000, Mayagüez , P.R. 00681-9000
}

\begin{abstract}
This paper presents coordinated ground-based observations by the NOAA-CREST Lidar Network (CLN) for profiling of aerosols, cloud, water vapor, and wind along the US east coast including Caribbean region at Puerto Rico. The instrumentation, methodology and observation capability are reviewed. The applications to continental and intercontinental-scale transport of smoke and dust plumes, and their large scale regional impact are discussed.
\end{abstract}

\section{INTRODUCTION}

Intra-continental and intercontinental transport of aerosol plumes (e.g. Asian dust, African dust, and biomass burning) play an important role in air quality and climate radiation studies. Global and regional chemical transport models and satellite sensors have been used to assess plume transport, but we still lack detailed knowledge of the vertical stratification of aerosol and their corresponding optical and microphysical changes during transport [1]. Multi-wavelength lidars are able to measure profiles of aerosol extinction and backscatter coefficient and thus the Angstrom exponent which contains information about particle size. In particular, a ground-based lidar network has the capability to observe the aerosol temporal-spatial distribution and variation in the regionalcontinental scale, such as EARLINET in Europe, MPL-Net in USA, AD-net in East Asia, and GALION on the global scale [2], thus providing the opportunities to verify the models and satellite products. In this study, we review the ground-based NOAA-CREST (Cooperative Remote Sensing Science and Technology Center) Lidar Network
(CLN) in the US east coast, the observation capability and applications on the smoke and dust transport are presented.

\section{LIDAR SYSTEM AND METHODOLOGY}

CLN is comprised of lidar facilities at mainly 4 sites (campuses) supported by the NOAA CREST Center (see Fig.1) [3-4]: City College of New York $(\mathrm{CCNY})$ in New York City $\left(40.821^{\circ} \mathrm{N} / 73.95^{\circ} \mathrm{W}\right.$; the University of Maryland, Baltimore County (UMBC, $\quad 39.255^{\circ} \mathrm{N} / 76.71^{\circ} \mathrm{W}$ ); Hampton University, Hampton, VA (HU, $37.02^{\circ} \mathrm{N} / 76.337^{\circ} \mathrm{W}$ ), and University of Puerto Rico at Mayaguez, PR (UPRM, $\left.18.30^{\circ} \mathrm{N} / 67.20^{\circ} \mathrm{W}\right)$. The CLN sites primarily deploy multi-wavelength elastic-Raman lidar for aerosol, cloud, PBL, water vapor observations. The elastic-Raman lidars are based on solid state Nd:YAG lasers with multiple wavelengths $(355,532,1064-\mathrm{nm})[5,6,7]$. The high pulse powers allow the observation and quantification of multi-layer plumes; and the multiwavelength capacity enables us to classify aloft aerosol type (smoke or dust). In addition, the use of Raman channels excited by the 355 -nm laser beam allows for a direct measure of water vapor and aerosol extinction profile. Observations from select CLN sites are available for over 8 years. More recently, rotational Raman temperature lidar has been deployed in the HU site and wind Doppler lidars have been deployed to characterize wind variability within the boundary layer at CCNY, $\mathrm{UMBC}$ and $\mathrm{HU}$, with the applications for PBL dynamic, low-level jet, wind resource assessment and validation and assimilation of winds in weather forecast models. 
Existing CLN lidars are either collocated with AERONET CIMEL sun/sky radiometers or are in near proximity. Simultaneous column aerosol optical depth (AOD) measured by AERONETradiometer is used to constrain the lidar-derived aerosol extinction profile and column lidar-ratio, this avoids an arbitrary assumption on lidar ratio that may result in the large retrieval error. In using multiple lidar systems, consistency checks between the different systems are warranted. In particular, we have made cross-validation checks of the CLNlidar algorithms for retrieving aerosol extinction and backscatter profiles. Relative differences are generally less than $5 \%$ below $7-\mathrm{km}$. CLN provides near real-time lidar images to local Environmental Agencies in MD, NY, NJ, CT, PR states.

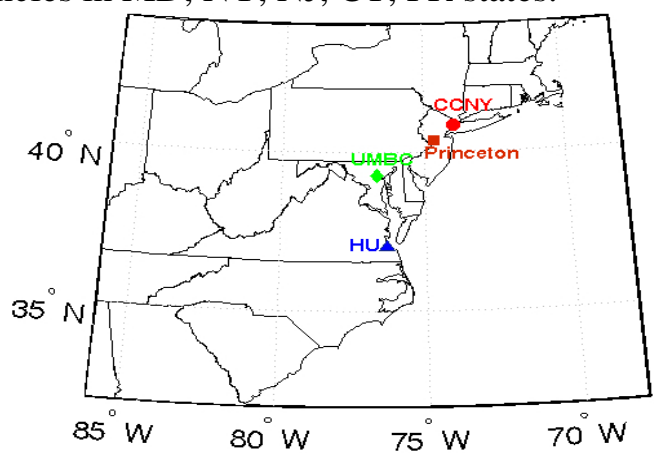

Fig. 1. NOAA-CREST lidar network sites.

\section{RESULTS and APPLICATIONS 3.1 Regional transport of Canadian smoke}

As an example, Figure 2 shows the time-height variation of aerosol by CLN on Aug.8, 2014. Aloft aerosol plumes can be clearly seen at CCNY, UMBC and HU sites. Both satellite GOES-AOD image and NOAA-HYSPLIT model indicate that the plumes are transported from Canada as shown in Fig. 3. Large Angstrom exponents $(\geq 1.8)$ from ARONET and MODIS satellite indicate that they are fine-mode dominant particles and thus associated with the smoke plumes transport. At CCNY-site, the column averaged lidar-ratios were obtained with values of $60 \sim 80 \mathrm{sr}$ at $532-\mathrm{nm}$ and 40 45 sr at 1064-nm, respectively. The aloft plumes contribute $80 \sim 90 \%$ fraction to the totalAODs. Importantly, the aloft plume heights show a decreasing trend with time at CCNY and UMBC sites, and even get close to PBL-top and mix downward after 16:00 at HU site. Such air subsidence and PBL entrainment mix the plumes down to the surface, thus resulting in air quality degradation.
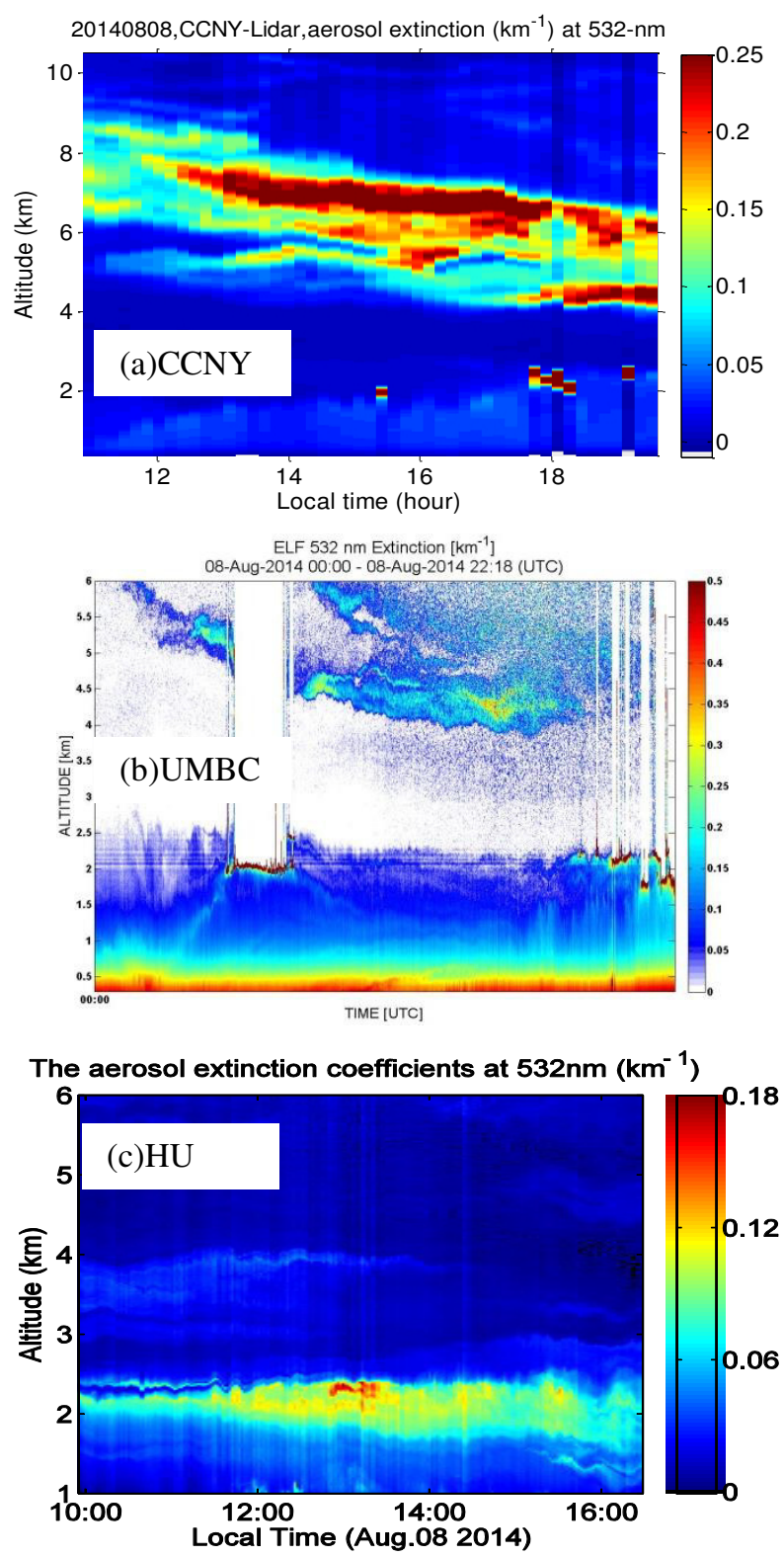

Fig.2. Smoke plumes transport to US east coast from Canada on Aug. 8, 2014. (a) CCNY, (b) UMBC, (c) HamptonU.

\subsection{African and Asian dust transport}

Figure 4 shows the time-height distribution of range-corrected lidar returns at Puerto Rico on July 1,2014 . The elevated aerosol layers can be seen at $2 \sim 4 \mathrm{~km}$ altitude. The co-located AERONETsunphotometer data indicates the coarse-mode dominant aerosols as shown in Fig.5. The HYSPLIT model shows that the air mass at 4-km altitude is transported from Africa for about 9 days. 
The high AOD and small Angstrom exponent from the MODIS/Aqua image indicate this event is African dust transport and the observed aloft coarse-model aerosols are the transported dust.

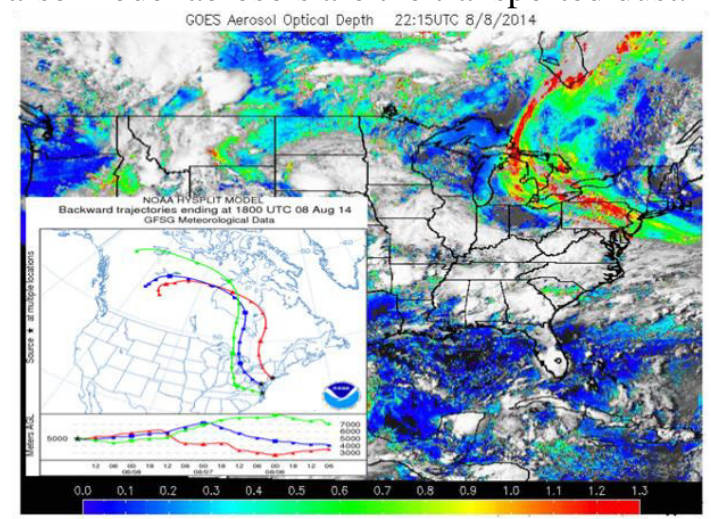

Fig.3 NOAA-GOES AOD and NOAA-HYSPLIT backward trajectories ending at 5-km, 18:00 UTC, Aug. 8, 2014.

In addition, the trans-Pacific transports of Asian dust in spring and mixture with other aerosols are also observed and characterized by CLN in the US East Coast [4]. The potential influence on the air quality and validation of model profiling prediction are verified [8]. A large scale transport episode observed by CLN in March 2012 is shown in Fig 6. Trajectory analysis and satellite data indicate that the multilayer plumes are mixture of trans-pacific dust transport to US $(>3 \mathrm{~km})$ together with mixed smoke and dust from south-southwest US.

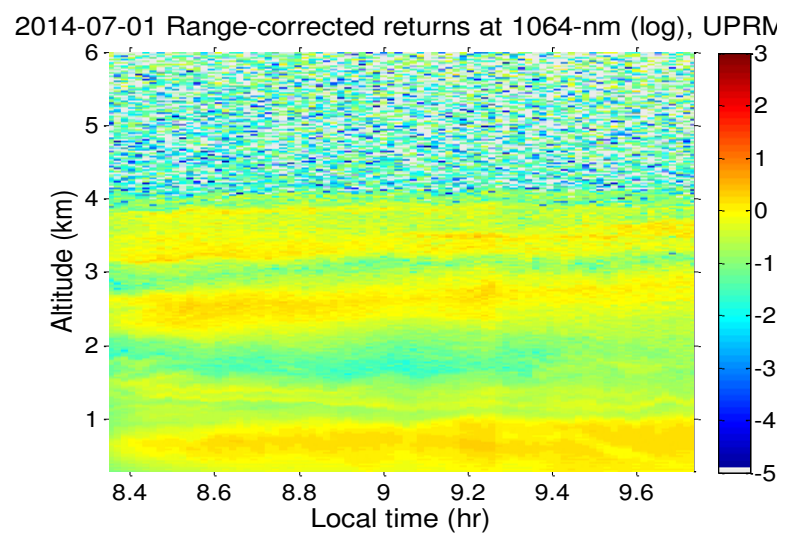

Fig.4. Range-corrected lidar returns at 1064-nm by UPRM lidar on July 1, 2014.

\section{CONCLUSIONS}

In summary, we present a coordinated groundbased NOAA-CREST Lidar Network (CLN) along the US east coast and the Caribbean region. The lidar systems have being used to profile aerosols, cloud, water vapor wind, and atmospheric structure demonstrate large-scale aloft aerosol plumes / process for climate, weather and air quality transport to the eastern United States that cause a
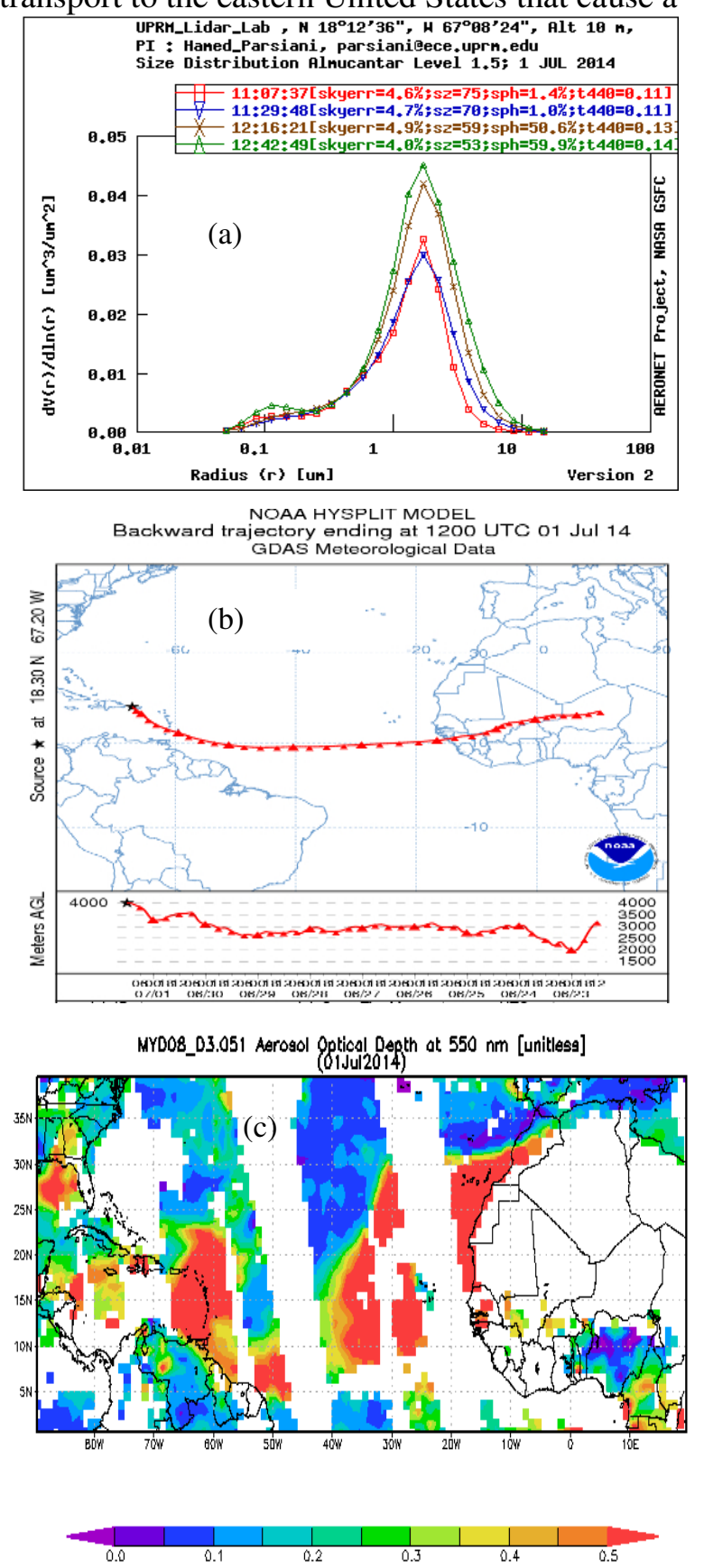

Fig.5 (a) AERONET aerosol size distribution, (b) HYSPLIT transport trajectory at $4-\mathrm{km}$ altitude, (c) MODIS/Auqa AOD on July 1, 2014.

significant change in aerosol optical properties and potential influences on air quality. CLN provides near real-time images to local Environmental 

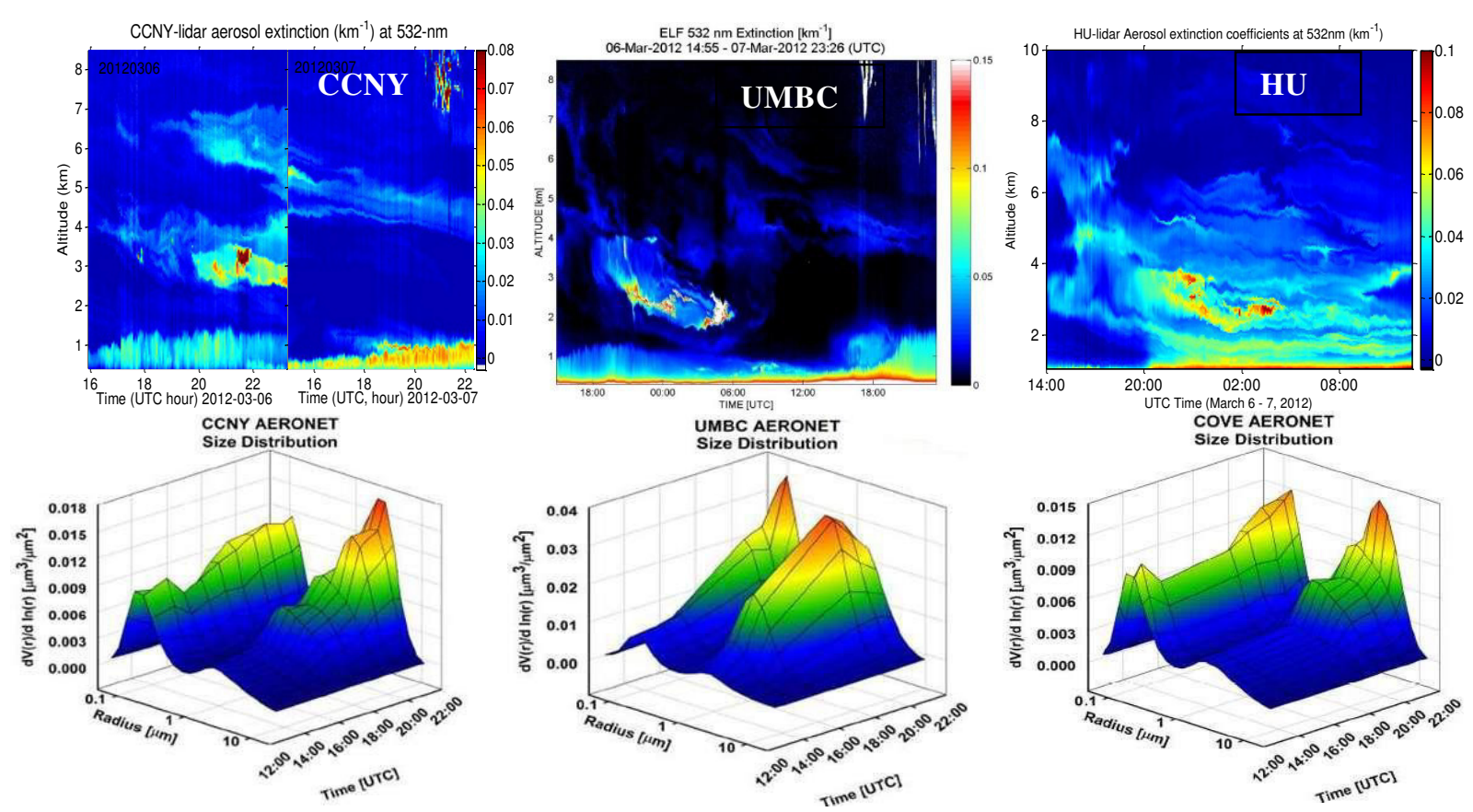

Fig. 6 Large scale plume transport observed by CLN sites at CCNY, UMBC and Hampton U on 03/06/2012 together with the corresponding NASA AERONET inversions at these sites.

Agencies in MD, NY, NJ, CT, PR states. CLN has been expanding its capabilities wind lidar observations at select sites, and plans are underway to expand the number of sites by including observations from other US lidar and ceilometers sites. Overall, the CLN observations help improve understanding of atmospheric physical and chemical processes/dynamics; validation of climate, weather and air quality forecast models.

\section{ACKNOWLEDGEMENT}

This study was supported by National Oceanic and Atmospheric Administration (NOAA) under the CREST Grant \# NA11SEC4810004. Authors greatly appreciate the data from NASAAERONET and NOAA-HYSPLIT projects.

\section{REFERENCES}

[1] National Research Council, Global Sources of Local Pollution: An Assessment of Long-Range Transport of Key Air Pollutants to and from the United States, National Academies Press, Washington, DC, 2009.

[2] Bosenberg, J., Hoff, R., Plan for the implementation of the GAW Aerosol lidar observation Network GALION, GAW report No.178, WMO/TD-No.1443, 2007.
[3] Hoff, R., F. Moshary, S. Ahmed, B. Gross, P. McCormick, H. Parsiani, CREST Lidar Network (CLN), CREST Publications Series, Vol.7: No.01 2009.

[4] Moshary, F., Cordero, L., Wu, Y., et al., Assessment of long-scale plume transport to the U.S. East coast using coordinated CREST lidar network and synergistic AERONET and satellite measurements, Proc. SPIE 8894, p. 88940K, 2013. [5] Wu, Y., Chaw, S., Gross, B., Moshary, F., Ahmed, S., Low and optically thin cloud measurements using a Raman-Mie lidar, Appl. Opt., 48, 1218-1227, 2009.

[6] Su, J., McCormick, M. P., Wu, Y., Lee, R. B., Lei, L., Liu, Z., Leavor, K., Cloud temperature measurement using rotational Raman lidar, J.Quant.Spectro.Rad.Trans.,125,45-50,2013.

[7] Compton, J. C., Delgado, R., Berkoff, T. A, Hoff, R. M., Determination of planetary boundary layer height on short spatial and temporal scales: a demonstration of the covariance wavelet transform in ground-based wind profiler and lidar measurements, J. Atmos. Oceanic Technol. 30 (7), pp. 1566-1575, 2013.

[8] Wu, Y., Han, Z., Nazmi, C., Gross, B., Moshary, F., A trans-Pacific Asian dust episode and its impacts to air quality in the east coast of U.S., Atmos. Environ., 106, 358-368, 2015. 